\title{
MINE HUNTING WITH DRONES
}

\author{
Philippe WAQUET
}

\begin{abstract}
This article deals with an important subject - mine hunting with drones. The author begins with a comprehensive overview, emphasizing the need for remotely controlled operations in mine warfare: mine reconnaissance, minesweeping, and mine neutralization. The advantages of semi-submersible vehicles and multibeam side-scan sonar technology are presented with a focus on the deployment flexibility with containerized units allowing an instant adaptation to any non-specialized vessel or shore facility. The article then presents in details the drone system architecture. Description and results of full scale operational evaluations conducted in 2001-2003 in Canada and in France demonstrate the excellent performance of a mine hunting drone system at sea.
\end{abstract}

\section{Overview}

\section{The Need for Remotely Controlled Operations in Mine Warfare}

Sea mines have proven to be a very deep concern for navies in the $20^{\text {th }}$ Century, as stated by Admiral Forrest Sherman, U.S. Chief of Naval Operations (CNO) in 1950: "When you can't go where you want to, when you want to, you haven't got command of the sea." ${ }^{1}$ The most recent war, Operation Iraqi Freedom in 2003, gives the last example of the strength and efficiency of this threat: "Although Iraq had little or no other means of striking out at the coalition shipping, these desultory attempts ${ }^{2}$ - even the simple threat of the presence of mines - proved once again that the weapons are a powerful deterrent, managing to slow coalition progress and deny access to the coast, if only for a relatively short time." ${ }^{3}$ To face this threat, the most promising approach allowed by today's technology is the use of remotely controlled platforms, which reduce the risk to human lives, as it is strongly recommended by Admiral Vernon Clark, U.S. Chief of Naval Operations (CNO): "We need to do everything we can to de-couple the hull of a ship from as many operational systems as we can." 4

Remotely controlled unmanned vehicles, that we may call "drones" even if they are not flying but just sailing at the sea surface, bring a great deal of operational advantages to mine warfare, starting with the possibility to keep it "organic" into the blue 
water force. Rear Admiral Paul Ryan, former Commander of the US mine warfare force (COMINEWARCOM), explains the first goal of this approach: "Organic MCM modules will provide an initial capability to enable naval forces to determine the extent of a mine threat and 'punch through' if required." 5 Furthermore, the inherent "modularity" of such systems opens a wide area of possibilities for a flexible operational organization: "The creation of a modular equipment which could be fitted on a wide number of craft of opportunity (COOP), (....and) can be pre-positioned or/and airlifted in-theatre for installation on locally available boats and crafts" ${ }^{6}$ matches the demanding requirements of fast deployment in amphibious operations, as well as it introduces cost-effective answers to the growing needs of homeland security.

Mine countermeasure missions can be split between various drones performing specific tasks: detection, localization, neutralization, sweeping ... This principle follows the rules of modern warfare: "The hallmark of a network-centric approach to warfare is that the act of sensing is separated from the act of attacking what the sensor revealed." 7

\section{Advantages of Semi-Submersible Vehicles and Multi-Beam Side-Scan Sonar Technology}

The considerable progress of technologies applied in unmanned underwater vehicles (UUV) during the past decade makes possible the achievement of all the mine hunting tasks: "It does not require much imagination to picture how an MCM UUV without a tether, with good endurance, range and autonomy, equipped with a proficient sensor suite and some form of mine disposal capability, could make an effective mine-detection, -localization, and, ultimately, a -neutralization platform - all with the human out of the minefield." 8

Among other alternatives for UUV, semi-submersible vehicles present the great advantage of a proven technology, thoroughly tested at sea in real conditions on mine fields, and superior to other concepts on several decisive points:

- An autonomous processing of sensor data and vehicle parameters under positive control through a radio link, allowing a permanent check of the mission progress, which is not possible with totally submerged vehicles,

- A mobility unmatched by AUV (autonomous underwater vehicle) with the high speed and endurance of diesel propulsion,

- A seaworthiness compatible with sonar stability requirements even in oceanic conditions, contrary to surface drones.

Side scan sonar has proven the highest performance in mine detection and classification since many years, with a sensor located near the sea bottom and unaffected by adverse environmental conditions. 


\section{Deployment Flexibility}

A drone system can provide a mine hunting capability fully integrated into standalone containers. It combines equipment for remotely controlled operations including a vehicle towing multi-beam side-scan sonar, and a containerized command and control system allowing an instant adaptation to any non-specialized vessel or shore facility.

A drone system can perform mine reconnaissance: assessing and monitoring the extent of the sea mine threat in an area where naval operations or maritime activities are considered. The missions are controlled from a command and control container carried by a vessel or installed ashore and located at a safe distance from the operation area, up to $15 \mathrm{~km}$. The vehicle is launched from a harbour and transits to the operation area by its own propulsion system, thanks to its high mobility and autonomy. A specific vessel is not necessary for handling the vehicle.

The system is designed to be operated and maintained by a small crew who is never exposed directly to the danger of mines. The command and control container can be installed in any location where a radio data link can be established with the vehicle. This location can be anywhere ashore or on board a ship having the required payload capacity. The large logistic autonomy of a drone unit allows a deployment far from the home base and without external technical support for long duration.

A typical mine hunting mission includes the following tasks:

- Preparing the vehicle on its cradle before the mission, and launching it by use of a standard crane from a quay or from a transport vessel. The vehicle can be launched and recovered in any harbour facility having the required water depth and crane capacity. This allows choosing a location as close as necessary to the operation area. The vehicle can alternatively be launched from any ship, military or civilian, having the required payload and crane capacity.

- Controlling the vehicle during its transit between the harbour or the transport vessel and the operation area. This control is performed remotely from a command and control container installed either ashore, or on the transport vessel, or on another vessel. The vehicle has its own capability of transiting by sea, with a speed, autonomy, and seaworthiness compatible with most encountered conditions for coastal navigation. The radio control for the safety of navigation during a transit requires only a small vessel.

- Controlling the mine hunting mission performed by the vehicle. This task includes the deployment, command and control of the tow fish carrying the side scan sonar. Sonar operations can be conducted at a speed up to 10 to 
$12 \mathrm{kts}$, which allows for a high area coverage rate, two to three times faster than with traditional means.

- After completion of the mine hunting mission, controlling the vehicle during its transit back to the harbour or to the transport vessel and recovery of the vehicle on its cradle.

During transit and operations, a surveillance of the traffic may be performed, if necessary, by a dedicated unit (e.g. police boat) to ensure the safety of navigation.

Except for the handling manoeuvres of launch and recovery of the vehicle, the crew is operating in the command and control container, which contains all the necessary equipment:

- One or two consoles for the management of the mine hunting task, operated at the level of the officer in charge of conducting the mission, and the command and control of the vehicle,

- One or two consoles for the operation of the side scan sonar: detection of "mine-like" echoes and classification.

An organization in two watches in order to perform a continuous operation on a full time basis (which is allowed by the large autonomy of the vehicle) requires a total crew of less than eight persons.

The hardware, including the vehicle with its sonar payload and the containers, is easily transportable by sea, air and road. ISO containers can be loaded with no delay on any transport system available.

During the delivery of each mine hunting drone system, the crew can be trained for operations and maintenance of the system, and with an appropriate Integrated Logistic Support (ILS) program the system can be operated and maintained by its crew without any further assistance from the Navy.

\section{Other Missions}

In addition to mine hunting missions, drones have a capability to perform minesweeping missions, when operational and environmental conditions require it.

The capabilities of a drone system apply to secondary missions that may be given by a Navy to make optimum use of the investment: hydrographical survey, search and rescue, and area and harbour surveillance.

\section{Description of a Drone System}

Open system architecture applies easily to "multi body" systems. It allows flexibility and future upgrade. A drone system is divided into three parts: 
- The "wet" segment,

- The "dry" segment,

- The "communications" segment.

\section{Wet Segment}

The wet segment consists of the following equipment, which are all deployed under the water during normal operations:

- An autonomous vehicle (also called drone);

- A sonar tow fish, towed body which carries the sonar antenna, and is equipped with a large horizontal motorized wing and at the stern four motorized aft planes performing dynamic attitude correction;

- The side-scan sonar antenna which comprises acoustic arrays, power amplifiers, reception electronics, and command and control electronics;

- The cable which links the sonar tow fish to the vehicle for mechanical towing, power supply transmission, and data communication;

- An underwater positioning system composed of a deployable range of acoustic buoys allowing a very high precision tracking of the sonar tow fish.

\section{Dry Segment}

The dry segment consists of the following equipment, which are all integrated into a container installed on-board the support vessel:

- data link interface electronics,

- vehicle man machine interface,

- vehicle computer,

- sonar man-machine interface,

- sonar computer,

- Command \& Control (C\&C) man-machine interface,

- $\mathrm{C} \& \mathrm{C}$ computer.

The dry segment has a distributed hardware architecture which can interconnect, through a $\mathrm{C} \& \mathrm{C}$ network, consoles and computers with other Combat System equipment when the container is embarked on a combat vessel.

This architecture may be updated by adding new computing power consoles to take into account future upgrades, such as mine disposal or mine sweeping.

If necessary, gateways are used to exchange data with other systems. 


\section{Communications Segment}

The communications segment provides radio data links between wet and dry segments.

- A low-rate bi-directional data link allows exchange of command and control orders and data (including, if applicable, Mine Avoidance Sonar) between the drone and the command and control container.

- Two high-rate mono-directional channels are necessary to allow video and sonar data to be transmitted from the vehicle to the command and control container.

\section{Actual Performance of Mine Hunting Drones at Sea}

As a typical example the recent achievement of a full scale evaluation at sea of the mine hunting drone "SeaKeeper" is described here. ${ }^{9}$

\section{Context}

Based on its experience in the design and production of several generations of MCM vessels, including the most successful "Tripartite" mine hunters, the French company DCN has developed SeaKeeper as an answer to face the challenging threat of modern mines. The considerable recent progress of communications and computer technologies were introduced by DCN engineers, skilled on the most advanced combat management systems such as the SENIT 8, into a remote mine hunting system.

The SeaKeeper vehicle is the well known "Dolphin" designed by International Submarine Engineering Research (ISER), Canada, with 12 units produced since 1982 for hydrography, and extensively tested by the US and Canadian navies for remote mine hunting. A full scale operational evaluation was conducted in 2001-2002 by the Canadian Department of National Defense / Defense Research and Development Canada (DND/DRDC), including tow-fish tracking and deep sonar trials (down to $200 \mathrm{~m}$ ) giving a complete satisfaction to Canadian authorities.

SeaKeeper (previously named "FDS3") was presented for the first time in Brest in June 2003 in the complete configuration including the DCN "dry segment". It was transported to Brest naval base in two ISO containers, and embarked on board the 500-t Support Vessel "Armorique" of the French administration (Phares \& Balises). The evaluation program conducted in June 2003 includes:

- Testing of a new sonar variant for DGA/DCE/GESMA and DND/DRDC,

- Evaluation by the French Navy,

- Presentations to foreign navies. 
A field of dummy mines laid in an exercise area near Camaret-sur-mer allowed for a full scale demonstration of the system capability to detect and classify the most dangerous modern mines from a safe distance of several kilometres. Each demonstration included the deployment from the naval base, with the SeaKeeper sailing by its own means under the control of the support vessel.

This evaluation gave a good example of the easiness of deployment of mine hunting drones for an urgent operation in a remote area.

\section{Demonstrations Objective}

SeaKeeper is the latest solution available for sonar reconnaissance against the most modern mines. With a vehicle remotely controlled by radio, it offers the highest level of safety for the crew, together with an unmatched performance in terms of area coverage rate. The system, integrated by $\mathrm{DCN}$, is raising interest in several navies over the world, and it became necessary to give a full scale demonstration in an actual theatre of MCM operations. Demonstrations were organized in June 2003 for this purpose, seizing the opportunity of an evaluation of the system in Brest for the French Navy.

The demonstration program included testing of a new sonar variant for DGA/DCE/GESMA and DND/DRDC, evaluation by the French Navy, and presentations to foreign navies. All the navies interested by this demonstration could not come to Brest, because of other activities, but more than 100 persons did attend.

In addition to the technical staff in charge of the evaluation, the French Navy sent several delegations from the Headquarters and from the forces, including a delegation led by Admiral Alain Dumontet, Flag Officer Naval Action Force (ALFAN).

\section{Operation Area}

The demonstrations took place in a mine hunter training area located near Camaretsur-Mer, at a distance of 5 nautical miles from Brest naval base. With a bottom of sand and gravels and a profile of small ripples, at depths between 25 and 40 metres, this area offers mine hunting conditions quite typical of the continental shelf off Brittany.

The French Navy evaluation was made in the "Goulet", a narrow channel leading to Brest road, with a harsh profile very demanding for MCM equipment.

In addition, some sonar scientific trials were performed in a specific pattern. 


\section{Environmental Conditions}

Wind and sea conditions were fair, with less than SS3, which made things easier but was not representative of the possibilities of the equipment, already demonstrated by previous trials performed up to SS6.

Current conditions are relatively difficult for MCM in this area, with tidal current up to 5 knots in the "Goulet", the maximum encountered during the demonstrations.

\section{Organization and Schedule}

\section{Demonstration Team Organization}

Sponsored by DCN, the demonstration was performed through a cooperation of several partners:

- The operations at sea were under the responsibility of GESMA, a research and trials centre of DGA (French MOD), specialized in mine countermeasures and having a level of expertise in mine-hunting techniques unique in the world. Operations were conducted under the supervision and control authority of the French Navy mine warfare specialists (ALFAN/MINES).

- The technical support was performed by DCN and its subcontractors, with the assistance of a Canadian team led by a delegation from the Defense Research \& Development Canada (DRDC).

\section{Shore Support}

Due to the self-contained design of the system, the shore support was very limited:

- The 40' container used for the transportation of the vehicle was also carrying the spares and tools necessary for the day-to-day maintenance of the system. This container was installed on the quay near the support vessel.

- Setting up the system, which came with the necessary cradles, required only basic handling facility (8-ton crane), as well as electric power and water.

\section{Support Vessel}

A support vessel was not necessary in itself for the inshore operation conducted, with the vehicle sailing within the range of control from the coast. However, it was worth demonstrating how the system can be deployed and operated from a ship.

The support vessel chosen for this role was the buoy tender "Armorique", belonging to the French administration. With a light displacement of 500 tons, a length of $47.50 \mathrm{~m}$ and a wide deck equipped with a crane, it featured the perfect example of a craft of opportunity (COOP) capable of hosting a SeaKeeper system. 
It took half a day to install the system on board, with the $\mathrm{C} \& \mathrm{C}$ shelter on starboard and the vehicle cradle beside it. Removable arrays were installed on the ship's mast for radio links.

\section{Time Schedule}

May 26, 2003:

Installation of SeaKeeper on board "Armorique"

May 27-28:

Mine laying in the exercise area and work-up trials

June 2 to 6 :

Scientific trials and demonstration for the French Navy

June 11, 16 and 19:

Evaluation for the French Navy

June 12:

Demonstration for DGA (French MOD)

June 13:

Press demonstration

June 17-18:

Demonstration for foreign delegations

June 20:

Equipment pack-up.

\section{Operation Scenario and Targets}

As the home port of the French Strategic Submarines, Brest is one of the most important theatres of operations for MCM vessels. Therefore, the operational scenario chosen for the demonstration was a full scale operation of mine reconnaissance in an area of the Brest approaches where a hypothetical mining was suspected.

The SeaKeeper C\&C shelter, stored permanently ashore, was embarked on board "Armorique" for a deployment. After the vehicle handling in the water in the harbour, both units, "Armorique" and the vehicle, left the quay and sailed out to sea.

During the transit, the SeaKeeper vehicle was maintained in line in front of the ship so that the officer of the watch could ensure its safety against incoming traffic. The transit speed, which could go up to 16 knots, was kept below 10 knots to satisfy the traffic regulations in the channel of Brest.

When arriving in the operation area, "Armorique" was kept apart from the dangerous area and the vehicle sonar tow-fish was deployed down to an altitude of $10 \mathrm{~m}$ above the seabed.

During the search, sonar operators were making a systematic recording of the position of any echo on the bottom. An analysis was made for each one on the basis of its dimensions and shape, so that all the bottom objects were recognised either as a nonmine bottom object-NOMBO (rocks, debris, etc.) or as a mine-like object (MLO).

Classification as MLO requires generally several observations from various orientations, in order to make sure of the shape in three dimensions. For this purpose the SeaKeeper tactical software generates automatically a "flower pattern" which is fol- 
lowed by the vehicle. It takes less than ten minutes to have, with this capability, a positive classification, which is faster than with traditional mine hunting techniques.

After completion of the sonar search of the area, the sonar tow fish was recovered and the SeaKeeper vehicle was guided back to the naval base.

Four mine shapes of the French Navy exercise inventory were laid in the exercise area:

- A cylindrical mine with a diameter of $0.53 \mathrm{~m}$ and a length of $2.5 \mathrm{~m}$;

- A spherical mine with a diameter of $1 \mathrm{~m}$;

- A Manta mine ;

- A Rockan mine.

In order to have a reference for the positioning performance of the SeaKeeper system, mine positions were measured precisely after mooring with the help of a diver carrying a GIB acoustic Beacon.

\section{SeaKeeper Configuration}

\section{Vehicle}

The SeaKeeper vehicle is a semi-submersible of the "Dolphin" family built by ISER. This prototype, belonging to DRDC under the name "Dorado," was thoroughly tested

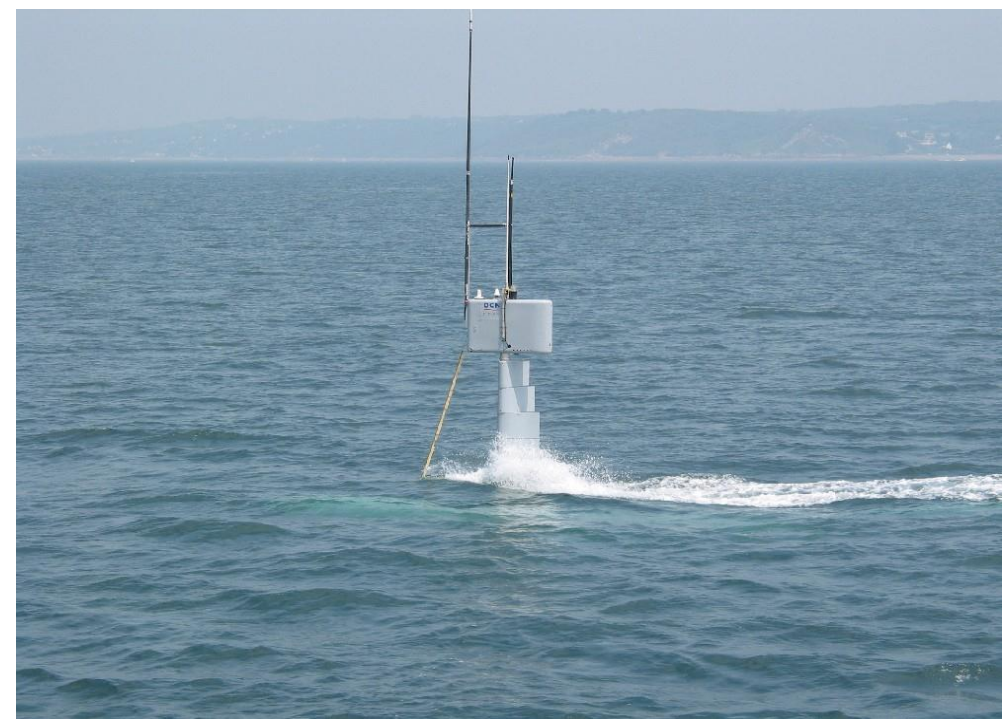

Figure 1: SeaKeeper Semi Submersible Drone at Sea (Photo DCN). 
during the Remote Minehunting System Technology Demonstrator (RMSTD) trials in 2001 and 2002. Tests were performed successfully including sonar and manoeuvrability trials with a towing depth down to $200 \mathrm{~m}$, sea-keeping trials up to SS6 and endurance trials.

For the evaluation in Brest, the vehicle was equipped for the first time with a bathymetric multi-beam echo sounder RESON SEABAT 8125.

The bathymetric multi-beam echo sounder was used for measuring the bottom profile, which is quite difficult to follow in canyons such as the "Goulet", with slopes up to $20 \%$. The bottom profile and 3-D bathymetry was displayed on two flat screens installed on the bridge of "Armorique" and used for programming the automatic towfish control. In the future, the multi-beam echo sounder software and display will be integrated into the $\mathrm{C} \& \mathrm{C}$ shelter.

\section{C\&C Shelter}

The SeaKeeper C\&C shelter (Figure 2), designed and integrated by DCN, was shown for the first time during these demonstrations. All the equipment necessary for controlling the system and conducting a mission is integrated in the shelter. In the configuration of the demonstrations, four consoles were used:

- Tactical console,

- Vehicle console (SCC),

- Two sonar consoles (SAC1 and SAC2).

The functions performed by the $\mathrm{C} \& \mathrm{C}$ shelter include:

- Management and display of the tactical situation, including sonar contact positions and an automatic computation of the search and analysis patterns to be followed by the vehicle;

- Control of the vehicle and tow fish, including a display of the vehicle mast head and keel cameras, and a display of the "Armorique" orientable camera following the vehicle;

- Sonar detection on a waterfall display in real time and on a page-by-page fix image display;

- Sonar classification on magnified images with a computer-aided device for measurement of echo and shadow dimensions, and a database of recorded images;

- Automatic calculation of positions using the GIB Aquatic software;

- CD-recording and printing of any data, including tactical maps, sonar images and reports. 


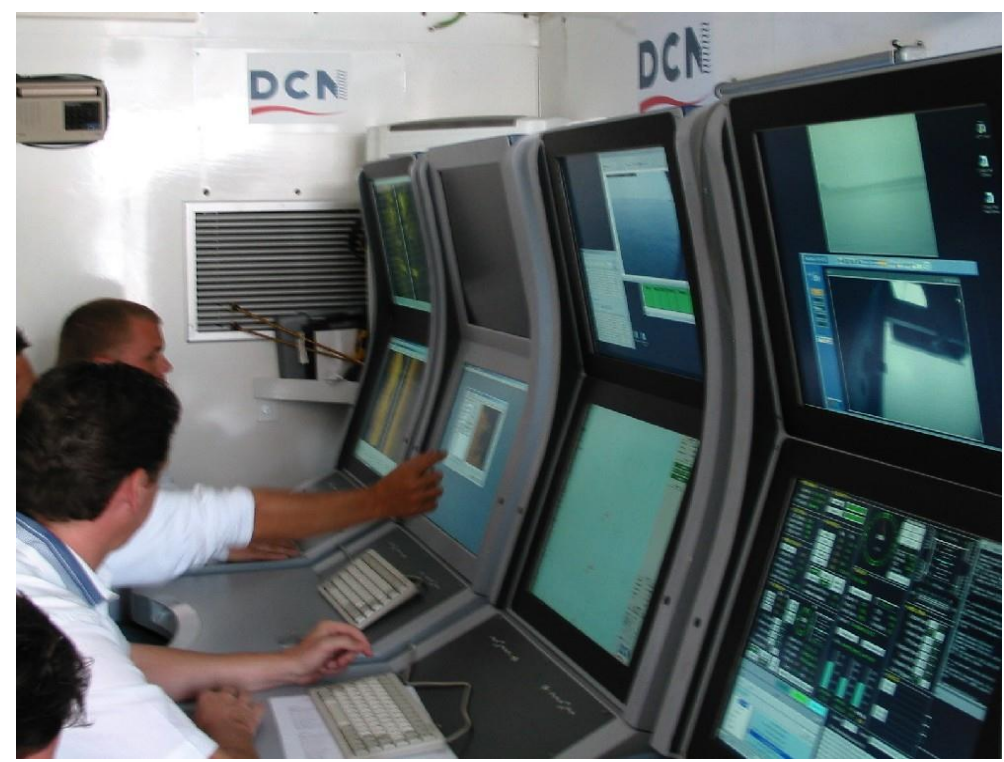

Figure 2: Mine Hunting Drone Command and Control Shelter (Photo DCN).

\section{GIB Precise Positioning System}

The SeaKeeper positioning precision was measured during the demonstrations with a GIB (GPS Intelligent Buoys) system made by ACSA.

\section{Results}

\section{Operational Availability}

During 13 days of trials and demonstrations, the SeaKeeper achieved more than 100 hours of sonar operation, showing a remarkable reliability for a prototype. A few failures occurred, which did not impact on the overall trial program, thanks to the logistic support brought with the system.

\section{Mine Search Performance}

All the mines laid in the area were detected by the system with a classification as a mine-like object.

The automatic track following on search patterns and classification "flower" patterns demonstrated the manoeuvrability and flexibility of use of the system, with a short turning radius and a capability of fast reconfiguration of the vehicle tracks. 


\section{Positioning Precision}

Measurement of the positioning error of each sonar contact on the targets gave a detailed knowledge of the performance of each of the subsystems used in SeaKeeper for MLO localization. The average positioning error on sonar contacts during the demonstrations was 2.5 meters.

\section{System Efficiency}

The system proved itself very fast and easy to deploy and operate:

- The average time for handling the vehicle in the water was 5 minutes.

- The average speed of transit was 9.5 knots, with a maximum of 16 knots and a speed limit of 5 knots in the naval base and 10 knots in the "Goulet."

- The average speed through water during sonar search was 10 knots, which allowed progressing even when facing a 5 knots current:

- This means a permanent availability of the system whatever the tidal conditions.

- It gave an area coverage rate three times faster than with traditional means.

- The use of a multi beam echo sounder on the SeaKeeper vehicle for piloting the tow-fish altitude on a harsh bottom profile proved very successful. 100\% sonar coverage was achieved even in areas with slopes of $20 \%$. Based on these results, it appears useful to adapt the SeaKeeper mission preparation software with the multi beam echo sounder information.

\section{Conclusion}

Mine hunting with drones is not anymore a future concept; it is a reality of today. A breakthrough in the endless fight of MCM against sea mines, it provides a cost-effective capability, available for any navy caring about safety for the crews during operations.

\section{Notes:}

1 Admiral Forrest Sherman, citation in "Warfare concepts," Naval Forces 3 (March 2003): 28.

2 of mooring mines

3 Nick Brown, "What Lies Beneath,” Jane's Navy International (June 2003): 14.

4 Admiral Vernon Clark, conference of the Mine Warfare Association (MINWARA) on 5 May 2003, citation in US Naval Sea Systems Command (16 May 2003). 
5 Rear Admiral Paul J. Ryan, USN, and Scott C. Truver, "US Navy mine warfare vision... programmes...operation: key to sea power in the $21^{\text {st }}$ century", Naval Forces 3 (March 2003): 37.

6 Massimo Annati, "Mine Hunting \& Mine Clearing Revisited," Military Technology 8-9 (September 2003): 48.

7 Norman Friedman, "World Naval Developments," Proceedings 129/8/1, 206 (August 2003): 4.

8 Commodore Paul Lambert, RN, UK Director of Equipment Capability (Under Water Battlespace), citation in "Unmanned Vehicles Enter the Underwater Battlespace," Jane's Navy International (December 2002): 16.

9 Sources: TTU Europe 463 (18 September 2003): 4; Janes International Defense Review (October 2003): 24.

PHILIPPE WAQUET is MCM Systems Project Department Manager at DCN (Paris) since 1993. He has worked on several projects on unmanned naval systems since 1996. He served in the French Navy from 1972 to 1992 . After serving as a clearance diver and a mine warfare officer on board several mine hunters and mine sweepers of the French Navy MCM force (1977-84), he was involved in new mine hunter projects as Deputy Vice-president of the French Navy Mine Warfare Studies centre (1984-86). He was Commanding officer of the tripartite mine hunter "Cassiopée" (1989-90), and Vice-president of the French Navy Diving and Underwater Studies centre (1990-92). He retired from the French Navy in 1992 with the rank of Commander. Mr. Waquet graduated with an Engineering Degree from the French Naval Academy (1972-75), and from the Naval War College, Paris (1987-89). He also holds an MBA from the San Francisco State University (1992-93). 